\title{
Two-State Solution to the Lottery Paradox
}

\begin{abstract}
Artūrs Logins
ABSTRACT. This paper elaborates a new solution to the lottery paradox, according to which the paradox arises only when we lump together two distinct states of being confident that $\mathrm{p}$ under one general label of 'belief that p'. The two-state conjecture is defended on the basis of some recent work on gradable adjectives. The conjecture is supported by independent considerations from the impossibility of constructing the lottery paradox both for risk-tolerating states such as being afraid, hoping or hypothesizing, and for risk-averse, certainty-like states. The new proposal is compared to views within the increasingly popular debate opposing dualists to reductionists with respect to the relation between belief and degrees of belief.
\end{abstract}

\section{Introduction}

Most of the existing reactions to the Lottery Paradox are revisionist with respect to epistemic justification. Typically, philosophers either suggest that epistemic justification is not closed under conjunction, or propose that high evidential probability alone is not sufficient for epistemic justification. Any of these proposals comes with certain theoretical costs, since both of the underlying principles (i.e. conjunction, and high evidential probability being connected to justification) are prima facie appealing.

The goal of the present paper is to suggest a new analysis of the source of the paradox. In a nutshell, it will be argued that the problem lies not within some perceived general aspect of epistemic justification, but rather that the paradox 
arises specifically because of a confusion about belief. More specifically still I will suggest that the paradox arises only when we lump together two distinct possible states of being confident that $\mathrm{p}$, under one general label of 'belief that p'. One of these states is more demanding than the other. One corresponds, roughly, to being maximally confident that $\mathrm{p}$, the other to being somewhat confident that p. More precisely still, these 'two states' correspond to two distinct ways of how the relevant inherent standards for being confident may be met: by having maximal confidence or by having some confidence. Given this more fine-grained distinction, the paradox disappears since these two distinct states of being confident that $\mathrm{p}$ differ with respect to which underlying principles they are supposed to comply with. Conjunction holds for the more demanding one, but not for the relaxed one. And, while one may be justified in being somewhat confident that a lottery ticket is a loser (given the statistical evidence only), one is not justified in being maximally confident that the ticket is a loser (given the statistical evidence). The conjecture of there being two separate states of being confident that $\mathrm{p}$ relies on insights from recent work on gradable adjectives. In particular it relies on insights about specificities of the adjective 'confident'. The two-state conjecture also fits well into a more general classification of mental states. It makes sense to distinguish between risk-tolerating states (risky states) on the one hand and less-risk tolerating or more certainty-like states on the other hand. One can be justified in having the former but not the latter towards $\mathrm{p}$ in cases where p doesn't have high enough probability on one's evidence. Being afraid that $\mathrm{p}$, suspecting that $\mathrm{p}$, hypothesizing that $\mathrm{p}$, supposing that $\mathrm{p}$ and so on are among the former. Being certain that $\mathrm{p}$, being sure that $\mathrm{p}$, as well as some factive emotions such as regretting that $\mathrm{p}$ seem to belong to the latter group. Importantly for us, it is impossible to construe versions of the lottery paradox both for certainty-like and for risky states. However, not for the same reason: it is never epistemically justified to be certain, sure, regret (and so on) that one's lottery ticket is a loser (on the basis of statistical evidence only), whereas while one may be epistemically justified in being afraid that one's lot- 
tery ticket is a loser, the conjunction principle doesn't hold for the risky states. The two-state conjecture fits nicely into this more general picture: being somewhat confident that $\mathrm{p}$ is associated with the group of risky states, while being maximally confident that $\mathrm{p}$ is associated with the certainty-like states. Actually, even more than that seems to hold. Accepting only a single state of belief without distinguishing the two more specific states of being confident that $\mathrm{p}$ has two substantial theoretical costs. First, it needs an additional theoretical explanation of why the state of belief stands out and cannot be classified within the two more general groups of states. In other words, the two-state conjecture seems to be a more parsimonious hypothesis in that it explains more without postulating an extra category. Second, it has an advantage over monist treatments of the lottery paradox in that it is more ecumenical with respect to our common sense intuitions in the context of the lottery paradox. The two-state solution can account for both why the conjunction principle seems to hold and why high evidential probability seems to matter for justification. Traditional treatments of the lottery paradox typically can account for one of these and have to propose an error theory for our intuitions with respect to the other. Thus, given these potential advantages, the two-state conjecture and a solution to the lottery paradox based on it is worth exploring in some detail.

The next section contains a quick rehearsal of the Lottery Paradox and its existing treatments. Section 3 provides a brief introduction to (some of the relevant aspects of) recent work on the linguistics of gradable adjectives. Section 4 applies the lessons from the recent work on gradable adjectives to confident. Section 5 elaborates the two-state conjecture about states of being confident that $\mathrm{p}$ based on the linguistic insights and provides more detail on how it can help to deal with the lottery paradox. Section 6 explores the more general classification of (relevant) mental states into risky and certainty-like states. The impossibility of constructing the lottery paradox for certainly-like and risky states is also explored. Section 7 connects the present proposal and in particular the two-state conjecture to the recent debate about credence-belief dualism. I explore simi- 
larities and differences between the present proposal and recent dualist views (i.e. recent views that postulate that both the graded notion of belief, i.e. credence, and categorical belief exist; cf. Ross and Schroeder 2013, Buchak 2014, Weatherson 2016, Weisberg, forthcoming) and some recent reductionist views (e.g. Clarke 2013, Greco 2015).

\section{The Lottery Paradox}

Consider the following argument.

\section{The Lottery Paradox (adapted from Kyburg 1961)}

(1.1) For all $\mathrm{S}$, for all $\mathrm{p}$, if $\mathrm{p}$ has high enough probability on S's evidence, then $\mathrm{S}$ is justified to believe that $\mathrm{p}(\mathrm{HIGH}) \mathrm{I}^{1}$

(1.2) For any ticket in a fair and large lottery, that ticket $n$ lost (tn) has high enough probability on S's evidence $2^{2}$

(1.3) $\mathrm{S}$ is justified to believe tn $[1.1,1.2]$

(1.4) For all $\mathrm{S}$, for all $\mathrm{p}, \mathrm{q}$, if $\mathrm{S}$ is justified to believe that $\mathrm{p}$, and $\mathrm{S}$ is justified to believe that $\mathrm{q}$, then $\mathrm{S}$ is justified to believe that ( $\mathrm{p}$ and $\mathrm{q})$. (CONJUNCTION)

(1.5) $\mathrm{S}$ is justified to believe that (ticket 1 lost, and ticket 2 lost, ..., and ticket $\mathrm{m}$ lost), where m: total number of tickets. $[1.3,1.4]$

(1.6) $\mathrm{S}$ is not justified to believe that (ticket 1 lost, and ticket 2 lost, ..., and ticket $\mathrm{m}$ lost) [Knowledge that one ticket won]

This presentation of the Lottery Paradox is slightly unorthodox in two ways. It is stated in terms of epistemic justification rather than rationality (Kyburg himself puts it in terms of rational acceptability), and more importantly, it doesn't make explicit use of the much discussed Lockean thesis that aims to connect rational degrees of belief to rational belief (Foley 2009, for instance). I be-

\footnotetext{
1'Justified' here and in all the remaining premises refers to propositional justification, not doxastic justification. See below.

${ }^{2}$ We are imagining a case where the lottery has already been drawn, but the results have not yet been announced. And S has no insider knowledge apart from the fact that the lottery is fair and has one winner.
} 
lieve that this way of presenting the paradox has the following advantages. First, on purely pre-theoretical grounds the ordinary notion of justification might be less elusive than the ordinary notion or notions of rationality (see, for instance, Williamson, 2017, forthcoming). Second, the present formulation is more inclusive. For instance, the HIGH principle is stated in a way that is easily compatible either with subjective Bayesianism or with other approaches to evidential probability. For instance, if one thinks that evidential probability just is subjective probability, which in turn corresponds to rational degrees of belief (a credence function), then one will take HIGH to be a part of the Lockean thesis. But one need not endorse subjective Bayesianism in order to appreciate the challenge raised by the Lottery Paradox. One may endorse an externalist or objectivist approach to evidential probability and still have the paradox (one may think that high evidential probability matters for justification).

A number of existing proposals aim to solve (or to dissolve) the Lottery Paradox. We can classify them in three broad groups $3^{3}$ (i) First, there are those who give up CONJUNCTION. Kyburg 1961, Foley 1979, Klein 1985, Christensen 2004, Kroedel 2012, and Timmerman 2013 are variants of this solution. A major difficulty for this approach is that while it manages to avoid contradiction and absurdity, it still allows for mutually inconsistent belief states. In other words, one is still justified in believing each of the lottery propositions (i.e. that ticket 1 lost; that ticket 2 lost; ...; that ticket $\mathrm{m}$ lost) and the proposition that not all tickets lost. The problem is that believing inconsistencies is ordinarily seen as a flamboyant sort of irrationality. It is difficult to accept that all of these mutually inconsistent beliefs are epistemically justified. What is more, the CONJUNCTION principle enjoys a high degree of intuitive plausibility. This approach to the paradox doesn't seem to be that popular nowadays. (ii) A more

\footnotetext{
${ }^{3}$ That is, the proposals that are not eliminitivist proposals with respect to epistemic justifiction (or rationality). A paradigmatic example of an eliminitivist reply to the lottery paradox (and other paradoxes) can be found in the later works of Quine. According to Roy Sorensen's (cf. Sorensen 2017) reconstruction of Quine's proposal, Quine is rejecting the very idea that 'justified' is a meaningful adjective. According to eliminitivism 'justified' is as meaningless as 'zillion'. Giving up on the idea that 'justification' is a meaningful term is one quite radical way of dissolving the paradox. In what follows we are setting aside such a radical eliminitivist view, though.
} 
popular approach is to give up HIGH. The old-school way of doing this was to add some defeat condition on HIGH (often to modify the Lockean thesis). See for instance Pollock 1990. The idea is that we restrain HIGH in such a way that it doesn't apply to the lottery propositions (or, perhaps, not to all lottery propositions). One worry, however, with such attempts is that given the variety of the lottery propositions, it is not clear how this kind of proposal can avoid ad-hocness if it manages to block the paradox at all (for a more elaborate and specific objection of this sort see Douven and Williamson 2006). Current trends among HIGH deniers include focusing on the sensitivity/safety conditions for justification that cannot (always) be satisfied by following HIGH (cf. Nelkin 2000); focusing on the apparent futility of statistical evidence for epistemic justification of beliefs (cf. Buchak 2014; Staffel 2016); the alleged need for a normalcy condition on justification (Smith 2010, 2016); and focus on the knowledge norm of justification (Williamson 2000, Littlejohn 2013). These recent attempts aim not only to avoid the contradiction but also to provide a new explanation of why, contrary to what it might initially seem, HIGH must fall. (iii) Another option, clearly less popular than the first two, is to reject premise (1.2) and hence to claim that it is not the case that for any ticket in a fair and large lottery, that the ticket lost has high enough probability on one's evidence. One may think, for instance, that 'high enough' evidential probability has to be 1 on one's evidence. And since the lottery propositions never get 1 , they never have high enough probability. Such a view may come close to Cartesian infallibilist epistemology, for on one understanding it is the claim that justification requires absolute certainty. Peter Unger seems to have defended a view along these lines (see Unger 1975; see also credence 1 contextualism, e.g. Clarke 2013, Greco 2015; we will come back to these more recent proposals in more detail in due course; see section 7 below). Another option would be to understand evidential probability in terms of knowledge, and to insist that since the probability of a lottery proposition never reaches 1 on one's knowledge, it is never high enough (Williamson's knowledge-first approach can be seen as proposing just this, even 
though the official knowledge-first story is rather in line with the rejection of $\mathrm{HIGH}^{4}$ ). Radically different motivation for rejecting (1.2) comes from reconsidering how belief-updating works (assuming the subjective approach to evidential probability). On such a view, (1.2) is false since for every lottery proposition that we will consider, the evidential probability will be different. In short, once one assigns a certain probability to lottery proposition number 1 , one will integrate this information into one's evidence set and hence it will matter for further probability assignments, e.g. for the probability assignment for lottery proposition number 2 and so on for all the remaining lottery propositions. Where proposition 1 will get $n-1 / n$ (n: total number of tickets in the lottery), proposition 2 will get $\mathrm{n}-2 / \mathrm{n}$ etc. But then, some of the lottery propositions will not have high enough evidential probability (for justification). This is a very rough presentation of Gilbert Harman's view (see Harman 1986). Unsurprisingly, this view has not attracted many followers. For one thing, it feels unpalatable, given that it entails that we can know through a priori reasoning alone which lottery ticket in a large and fair lottery has the best chance of winning, indeed, we can know on this view that a lottery ticket in, say, a one million ticket lottery has 999999/1000000 chances of winning.

Note also that the existing proposals according to which some of the terms involved in the formulation of the Paradox are ambiguous (or the truth conditions for justification attributions vary with respect to situations) and hence, no contradiction really follows (cf. Cohen 1998, Lewis 1996, and arguably, Leitgeb 2014, 2017) are not, strictly speaking, a distinct option from (i), (ii), or (iii). For what this option is really suggesting is that there are distinct readings of one or more notions involved in the paradox and on one of the readings a given principle will hold while on another it fails. Contextualists may be suggesting that in one sense HIGH holds but in another fails, and/or in one sense CONJUNCTION holds and in another fails.

In what follows I will propose a new alternative approach with respect to the

\footnotetext{
${ }^{4}$ Though see Smith 2016: 65 for a dissenting interpretation.
} 
lottery paradox. The new proposal is inspired by some recent work on gradable adjectives. The next section introduces a brief summary of the relevant aspects of this work in linguistics ${ }^{5}$

\section{Gradable Adjectives: a very rough introduc- tion to a recent approach}

It is accepted that some adjectives are gradable, while others are not. Typically, the two differ in their behaviour in comparative constructions, in comparative questions, and in combination with degree modifiers. Namely, a gradable adjective will typically be accepted in comparative constructions, comparative questions, and with degree modifiers, whereas a non-gradable one will be odd in such constructions (as long as we focus on standard, ordinary contexts and on non-forced or special uses). See for instance:

(1) This wall is taller than that wall.

(2) How smart is your dog?

(3) Tap water in our city is completely pure.

(4) ? This step was more previous than that ${ }^{6}$

(5) ? He was slightly/maximally married.

Tall, smart, pure are all gradable, whereas previous, and married are nongradable adjectives.

According to one highly popular view, gradable adjectives can be best understood by appeal to degrees (see Bartsch and Vennemann 1972, Cresswell 1976, Heim 1985, Kennedy 1999, 2007 among many others). The basic idea within this framework is that gradable adjectives denote a measure function. Roughly put, a gradable adjective's meaning is a function that maps entities (individuals) to degrees on a scale.7 Now, in order to fully understand gradable adjectives

\footnotetext{
${ }^{5}$ In what follows I rely mainly on the recent work by Chris Kennedy. See Kennedy and McNally 2005, Kennedy 2007, forthcoming and further references therein. See also Cariani, Santorio, and Wellwood ms. for an alternative approach.

6'?' indicates infelicity.

${ }^{7}$ So, for instance, the interpretation of the adjective tall will be (on some accounts) as
} 
we need to appeal not only to degrees, but also to relations that hold among degrees. It is intuitive to theorize the relations between degrees by appeal to scales. So, for instance, to say that one wall is taller than another one is to say that the degree of the former exceeds the degree of the latter on the relevant scale of height. In brief, scales are taken to allow orderings of degrees (along a relevant dimension). Uncovering properties of the underlying scale is crucial for a theoretical understanding of a gradable adjective.

Gradable adjectives introduce a threshold (or an endpoint; see below), relative to a degree on a scale. Only when a threshold or an endpoint has been fixed an expression containing a gradable adjective can denote a property ${ }^{8}$

In addition to distinguishing between gradable and non-gradable adjectives it has become increasingly popular to make further distinctions among gradable adjectives. For it has been observed that there are robust differences among the gradable adjectives. They don't all respect the same patterns of inferences, they don't behave in the same way when combined with different degree modifiers, and they seem to exhibit varying sensibilities to shifts of context (cf. Unger 1975, Kennedy 1999, 2007, Kennedy and McNally 2005, Rotstein and Winter 2004). To begin, there are what have been called relative gradable adjectives on one hand, and absolute gradable adjectives on the other (cf. Unger 1975, McNally and Kennedy 2005). The following examples provide a rough idea of some general differences in behaviour of these two sorts of gradable adjectives (it is assumed that (6a) and (7a) are true):

\section{Entailment with antonyms}

(6) (a) Mike is not tall.

\footnotetext{
follows: «tall $=\lambda d \lambda x \cdot \operatorname{tall}(x)=d$ (cf. Kennedy and McNally 2005: 349). Roughly, tall is a measure function that has an individual as an input and the individual's degree of tallness as its output, that is, a degree on the scale of height (or, perhaps more precisely, on the scale of vertical extension). Measure functions are of the type $\langle e, d\rangle$. They take individuals and return degrees.

${ }^{8}$ See Kennedy: "One feature that all analyses [of gradability] agree on, however, is that gradable adjectives are distinguished from their non-gradable counterparts in introducing (either lexically or compositionally) a parameter that determines a THRESHOLD of application, such that a predicate based on a gradable adjective holds of an object just in case it manifests the relevant property to a degree that is at least as great as the threshold. A predicate expression formed out of a gradable adjective therefore comes to denote a property only after a threshold has been fixed." Leffel et al., ms.
} 
(b) ? Mike is short.

(7) (a) Water in Chernobyl is not pure.

(b) Water in Chernobyl is impure.

\section{Degree modifiers}

(8) (a) This sample of water is completely pure.

(b) Tap water is slightly impure.

(c) The glass is half full.

(9) (a) ? Mike is completely/slightly/half tall/short.

(b) ? The purse is completely/slightly/half expensive/cheap.

In short, absolute adjectives respect entailment in pairs of antonyms. For instance, if something is not pure, then it is impure ((7a) entails (7b)). This, however, doesn't hold for relative adjectives. If someone is not tall, it doesn't follow that she/he is short (from (6a) we cannot infer (6b)). Examples in (8)-(9) show that some gradable adjectives don't combine with certain degree modifiers, while others do. According to Kennedy and McNally (Kennedy and McNally 2005, Kennedy 2007) this is another notable difference between relative gradable adjectives and absolute gradable ones. The difference between the two is theorized within their framework by appeal to structural differences in their underlying scales.

Very roughly, there are two general sorts of scales: open scales and scales that are not open. Relative gradable adjectives have open underlying scales, whereas absolute adjectives have scales that are not open. An open scale has no maximal or minimal elements. There is no endpoint on an open scale (only thresholds of application that are determined contextually). For instance, there is no limit, in principle, to how expensive or how cheap something can get. Prices could always grow and labour could always get cheaper. Scales that are not open in this sense can be either totally or partially closed. A totally closed scale has both maximal and minimal elements. For instance, it seems that for a glass of water to be full it has to have already a good amount of water in it. It also has a maximal limit of how much wine it can contain. Opaque, transparent, open 
and closed are other plausible examples of totally closed scales. Partially closed scales can be closed by having a lower or an upper endpoint. That is, there are partially closed scales that have minimal but not maximal elements and there are scales that have maximal but not minimal elements. For instance, dry has a maximal element scale - for something to be dry it has to be maximally dry. Wet also has a partially closed scale, but it is a minimal endpoint scale. For something to be wet, it has to be at least somewhat wet.

Maximal standard absolute gradable adjectives (i.e. adjectives with scales that have maximal but not minimal elements) can be distinguished from minimal standard absolute gradable adjectives (i.e. adjectives with scales that have minimal but not maximal elements) on the basis of their behaviour with degree modifiers and their entailment patterns (among other things) 9

Typically, maximal adjectives can be felicitously combined with modifiers 'completely', 'perfectly', 'absolutely' and the like, while they cannot be felicitously combined with modifiers 'slightly', 'partially' and the like (that is, without forcing a special, non-standard interpretation). Minimal standard absolute adjectives, on the contrary, can be felicitously used with modifiers like 'slightly', 'partially' and the like but not with 'completely', 'perfectly' and alike (again, in their typical or standard usages). Adjectives allowing for both maximal and minimal standards, can be combined with both sorts of modifiers (but see below). Note also that relative adjectives cannot felicitously be combined with either sort of modifier (in standard, typical cases). See, for instance, the following examples:

(10) (a) The road is completely dry.

(b) ? The road is slightly dry.

(11) (a) The table is slightly wet.

(b) ? The table is completely wet.

(12) (a) The window is completely opaque.

(b) The window is slightly opaque.

\footnotetext{
${ }^{9}$ See Kennedy 2007, for instance, for further criteria, such as the behaviour of the adjectives in Sorites-paradox-style reasoning.
} 
(13) (a) ? This wall is completely tall.

(b) ? This wall is slightly tall.

(10a), (11a), (12a), and (12b) are felicitous, while (10b), (11b), (13a), and (13b) are not. I refer to Kennedy and McNally 2005 and Kennedy 2007 for further theoretical explanation of how these observations are predicted given the classification of underlying scales introduced above.

Another important set of observations that allows us to distinguish different absolute gradable adjectives comes from considerations about patterns of entailments. Consider the following examples:

(14) (a) The road is wetter than the sidewalk.

(b) The road is wet.

(15) (a) The floor is drier than the wall.

(b) The wall is not dry.

(14b) seems to follow from (14a), which is a pattern proper to minimal standard absolute gradable adjectives. If it were not the case that a minimal amount of moisture is enough for one to be wet, then we could not infer that A is wet from A being wetter than B. (15b) seems to hold, given the truth of (15a). The pattern here is proper to maximal standard adjectives. It cannot be true both that the floor is drier than the wall and yet that the wall is maximally dry. If the degree of the dryness of the floor exceeds that of the wall, then the degree of the dryness of the wall cannot be maximal. The fact that (15b) seems to hold given (15a) indicates that dryness has a maximal standard.

At this point, it is important to clarify that adjectives that have totally closed scale have somewhat more nuanced behaviour. Typically, they will combine well with degree maximizers (like 'completely'), but may have some mitigated results with 'slightly' and the like. For instance, while 'completely full' is acceptable, 'slightly full' appears not so great. Once more I refer to Kennedy and McNally 2005 and more specifically to Kennedy 2007 (in particular section 4.3.) for further theoretical explanations of these observations. In short, it seems that for pragmatic reasons stronger interpretations are always favoured to weaker ones. 
Moreover, maximum standard interpretations entail minimal ones. Hence, it should not be surprising that, other things being equal, we observe that totally closed scale adjectives have a tendency to behave more similarly to maximum standard adjectives than to minimum standard ones. This being said, there are, of course, cases where totally closed scale adjectives behave equally naturally with 'completely' and 'slightly' and the like. For instance we have seen this already with (12a) and (12b) (i.e. 'The window is completely/slightly opaque'). Similarly, it seems that 'slightly' and 'completely' also combine well with 'transparent' (e.g. 'The window is completely/slightly transparent') ${ }^{10}$ Furthermore, it appears that adjectives with closed scales will not respect entailment patterns that apply to maximum standard adjectives (nor those of minimum standard adjectives). For instance, given that my glass of wine is fuller than yours it neither follows that my glass is full, nor that your glass is not full.

It is equally noteworthy that only relative adjectives are utterly contextsensitive. However, to say that only relative adjectives are utterly contextsensitive is not to say that there is no context dependence whatsoever in the case of absolute adjectives. The truth conditions for relative gradable adjectives can vary; they depend on standards of comparison which are fixed by context. The truth conditions for absolute gradable adjectives do not vary in this way; they depend on fixed standards of comparison (that are encoded lexically). For instance, whether an $x$ will count as tall will depend on whether $x$ stands out in comparison to a relevant class of other objects/individuals. The standard of comparison for tall is shifty; the threshold depends on a comparison class. For instance, Ana might count as tall when compared to other kids of her age, but will not count as tall if compared to adults. Whether an $x$ counts as dry, on the other hand, doesn't depend on whether $x$ has reached a threshold that is defined by a reference to a contextually determined comparison class. By default, $x$ will count as dry given that $x$ has a maximum of the dryness property. Similarly,

\footnotetext{
${ }^{10}$ See Kennedy 2007: 37-38 for more details on contexts where 'opaque' and 'transparent' may have minimal interpretations and contexts where they may have maximal interpretations, e.g. cases where one is manipulating the degree of tint of a car window, going from completely transparent to completely opaque and vice versa.
} 
an $x$ will count as wet, given that $x$ has at least some minimal wetness. The standards of comparison for absolute gradable adjectives are endpoint-oriented. And yet there is room for context to contribute to truth conditions also in cases of absolute adjectives. The context dependence in the case of absolute adjectives is, however, radically different from the one we observe in relative adjectives. Namely, relative adjectives involve vagueness, whereas absolute adjectives can be imprecise but not vague. Applications of relative adjectives are utterly uncertain, whereas in the case of absolute adjectives we often have certainty whether something has the relevant property. Phrases involving absolute gradable adjectives can be made more precise, by precisification (we may, for instance, make it precise that we want to know whether a glass is full in a sense that it may not contain more wine). In short, while absolute adjectives might be imprecise, only relative ones are genuinely vague-utterly context-sensitive.

\section{The double life of confident}

After that excursion into the linguistics of gradable adjectives we are in a position to draw some conclusions about confident. First, it is presumably uncontroversial that confident should be considered a gradable adjective. For it can be felicitously used in a comparative form, as illustrated by (16).

(16) Jim is more confident that Jane will come, than Jack is.

Arguably, it is also intuitive to classify confident as an absolute gradable adjective. It seems to be an endpoint rather than a contextually determined threshold-oriented. Consider the tests from entailments with antonyms and tests with degree modifiers:

(17) (a) Jim is not confident that Brazil will win.

(b) Jim is doubtful that Brazil will win.

(18) (a) Jim is completely/totally/absolutely confident that Laura will call him. 
Assuming that (17a) is true, (17b) seems to follow. This is a good indication that confident is an absolute and not a relative adjective, since absolute adjectives and not relative adjectives respect this sort of entailment from a negation to a positive claim about its antonym (assuming that doubtful is an antonym of confident). Compare these examples also to the paradigmatic cases of (6a) and (6b). Confident doesn't behave like a relative adjective in this respect (from the fact that someone is not tall, it doesn't follow that he is small). Furthermore, confident also appears acceptable with degree modifiers that don't combine with relative adjectives, but are only acceptable with absolute ones; see (18a) (compare to (8)-(9)) ${ }^{11}$

A more tricky question is: what kind of absolute adjective is confident? At first glance, it might seem that confident is an absolute maximal standard adjective. Maximal ones combine well with completely and other maximizing degree modifiers, but are odd in combination with minimizing degree modifiers, like slightly or minimal. As it appears, confident not only combines well with completely, but provides poor results with slightly. See (19):

(19) ? Jim was slightly confident.

However, as we observed above, tests with slightly don't always allow us to determine whether an absolute adjective is a minimal standard only adjective or an adjective having both a minimal and a maximal standard. For some adjectives that have a totally closed scale will be acceptable with completely and not so much with slightly. As we saw, full is acceptable with completely but not with slightly. Hence, the mere fact that confident has poor results in combination with slightly and the like doesn't suffice to classify it as a maximal standard absolute adjective.

Moreover, note that confident appears to be acceptable with some further modifiers. Crucially, paradigmatic maximal standard adjectives are not acceptable with these further modifiers. Consider, for instance, (20)-(21):

\footnotetext{
${ }^{11}$ One place where confident is assumed to be a relative adjective is in Unger 1975: 63-65. However, the problem there seems to be that Unger focuses exclusively on the combination of confident with the specific modifier rather and doesn't consider other relevant data and possible interpretations of his proposal.
} 
(20) (a) That's a lot of history for Baffert and Smith to overcome, but they can feel somewhat confident because Justify has won all three of his starts this year. (From: http://bleacherreport.com/articles/2773656kentucky-derby-2018-post-positions-latest-vegas-odds-and-picks-afterpost-draw)

(b) Frankly, after the Q2 results had come out, we were more or less confident that the entire corporate bank pack had ended up bottoming out. (From: https://economictimes.indiatimes.com/markets/expertview/betting-on-these-3-themes-for-next-1-year-prasanth-prabhakaranyes-securities/articleshow/63697836.cms)

(c) Were you half-confident that an RTM might just be reserved for you? To be honest, it wasn't half. I was fully confident that I would go to Mumbai Indians and they'll use the Right to Match card for me. (From: https://www.hindustantimes.com/cricket/was-confidenti-would-go-to-mumbai-indians-in-ipl-auction-krunal-pandya/ story-skbS25qfhx052VRrErnz2O.html)

(d) I was sort of half confident I was going to get there but the line was coming up pretty quick, so I had to stick my head out a bit. (From: https://thewest.com.au/sport/horse-racing/silverstream-snares-thrillingwin-in-waroa-lee-steere-stakes-ng-b88657151z)

(21) (a) ? This sample of water is somewhat/more or less/half/sort of half pure.

Examples in (20) are acceptable. However, parallel cases with the same modifiers applied to paradigmatic maximal standard absolute adjectives are odd.

Finally, all of these 'non-classic' modifiers seem absolutely felicitous in combination with paradigmatic minimal-and-maximal standard absolute adjectives (the totally closed scale adjectives). Consider, for instance, (22):

(22) (a) The glass of water is somewhat/more or less/half/sort of half full.

These observations seem to speak in favour of classifying confident as an adjective that has both maximal and minimal standards. 
Furthermore, and perhaps even more importantly, confident doesn't seem to respect the entailment patterns that are typical of maximal standard adjectives (such as the pattern in (15a)-(15b)). Consider (23):

(23) (a) Laura's parents are more confident that God exists than she is.

(b) ? Laura is not confident that God exists.

It seems that (23b) doesn't follow from (23a). For the truth of (23a) is compatible with Laura being confident that God exists. Perhaps she is not as confident as her parents are, but still, she may count as a believer and as being confident in God's existence. Such a possibility implies that confident doesn't behave here as a maximal standard adjective. The best explanation here seems to be that confident has this double life: it has both maximal and minimal standards. It has two standards. And in this case, the minimal standard interpretation is prevailing. In this context we are focusing only on the minimal standard. Note also that confident violates the entailment pattern for mere minimal standard adjectives as well (the pattern observed in (14a)-(14b)). See, (24):

(24) (a) Jim is more confident that there will be World War III than that there are aliens.

(b) ? Jim is confident that there will be World War III.

(24b) doesn't appear to follow from (24a). It may well be the case that Jim is neither confident that there will be WWIII, nor that there are aliens. It is merely that he is closer to being confident that there will be WWIII than he is to being confident that there are aliens. It seems that in such a situation, the prevailing interpretation is the maximal standard one, not the minimal.

In sum, if we are to adopt a widely held view within contemporary linguistics of adjectives, then it seems that we should treat confident as an adjective that has two standards: a minimal and a maximal one. Depending on the situation, it will be best interpreted as requiring a maximal or only a minimal degree of confidence. 


\section{A plea for a two-state solution}

With the above results about confident at our disposal we are now in a position to explore some hypotheses about the state of being confident and its standards. That is, if we take the above conclusion about the double life of the adjective confident at face value, then a certain picture of the state of being confident seems to emerge. It is commonly accepted that being confident comes in degrees. However, contrary to a popular idea, there is not one (in a sense categorical; see below) state of being confident that $\mathrm{p}$, such that whether one is confident that $\mathrm{p}$ is determined by some (contextually or arbitrarily) set threshold on the scale of confidence. Rather there are two possible states of being confident that p. One is the state of being minimally/somewhat confident that p. The other is the state of being maximally confident that p. The minimal one is such that any degree of confidence that $\mathrm{p}$ is enough for one to be confident that $\mathrm{p}$ (in this sense). The maximal state is such that the maximal amount of confidence is required for one to be confident that $\mathrm{p}$ (in this sense). Both are endpoint-oriented states; the former is a minimal endpoint state, and the latter is a maximal endpoint state 12

Now, the idea that I would like to put on the table in what follows is that there are two distinct states of belief that we have a tendency to collapse (under one label of (categorical) 'belief'). This tendency then gives rise to a confusion that ultimately generates the lottery paradox. The proposal is that there is a state of belief that requires little on the one hand, and a more demanding

\footnotetext{
${ }^{12}$ Alternatively, one might think that being confident that $\mathrm{p}$ is determined somewhat contextually (in a restricted sense of contextualism): in 'minimal-standard' contexts being confident that $\mathrm{p}$ requires any amount of confidence, whereas in 'maximal-standard' contexts being confident that $\mathrm{p}$ requires the maximal amount of confidence. One might think of being confident that $\mathrm{p}$ within this double standard contextualism by analogy to a similar view about being full. On some occasions, a glass containing an amount of liquid that fills, say, $2 / 3$ of the glass (or perhaps even less) will count as a full glass. On other occasions, nothing less than a glass filled to the brim will count as a full glass. Let me stress that what counts as being confident, or being full for that matter, is not utterly context-dependent on such a view. There are only two possible standards: a minimal standard and a maximal one. And they are fixed in a sense. Details about the context will matter for determining which sort of standard applies in a given situation. For matters of clarity, I prefer the simpler view above. Nevertheless, I think that the solution to the Lottery Paradox that I will sketch below could also be transposed into the minimal-maximal restricted contextualist framework.
} 
state of belief on the other hand. Crucially, the two states don't have the same standards for epistemic justification, and they don't validate the same principles of the logic of justification.

More specifically, the two-state conjecture that I would like to put forward here is the following thought. (It is a thought that unifies in a sense the ideas of the two precedent paragraphs.) When we talk about belief (that p) we may be actually talking about one of the more specific states. We may be talking either about the state of being maximally confident (that p) or about the state of being somewhat (minimally) confident (that p). On many occasions the difference will not matter, so it is often harmless to talk about belief in general and not make the more fine-grained distinction between the two possible states of being confident. However, on some occasions having the more fine-grained classification will be crucial. Notably, in the context of the lottery paradox, it matters substantially whether we are talking about belief in the sense of the state of being maximally confident that $\mathrm{p}$, or in the sense of the state of being somewhat confident that p.

Three clarifications are in order before considering how exactly the two-state conjecture can help to deal with the lottery paradox. First, when I say that there are two (distinct) states of being confident that p, I don't mean that we can be simultaneously in two distinct mental states of being confident that $\mathrm{p}$ at any given time. We cannot be at the same time maximally confident that $\mathrm{p}$ and somewhat confident that p. So, in a sense, what I call 'two states' are not entirely two fully independent entities. It is rather that there are two endpointoriented standards that determine how much confidence is required for being in a state of being confident that p. The possibility of two states is somehow dependent on there being these two absolute standards. Compare to the case of being opaque, or being transparent. It is intuitive that in some, e.g. demanding contexts, what counts as a state of being transparent will be determined by a maximal standard-only complete, $100 \%$ transparency will count as a state of being transparent. In other maybe more relaxed contexts a barely minimal level 
of transparency will be enough for something to count as being in a state of being transparent ${ }^{13}$ The proposal that there are two possible states of being transparent does not entail that something can be simultaneously in both of these states (e.g. the state of being minimally transparent and the state of being maximally transparent). Similarly in the case of being confident that $\mathrm{p}$, the present claim is that depending on context to be confident that $\mathrm{p}$ may require a maximal or a minimal standard of having confidence.

Second, at minimum, the present proposal can be seen as merely stating that being confident that $\mathrm{p}$ is what the adjective 'confident' in its positive (i.e. non-comparative) form corresponds to. And in some contexts it corresponds to being only somewhat confident, while in all other contexts to being maximally confident. Such a formulation of the two-state conjecture may appear somewhat misleading, though. One might think that the claim that there are only two states of being confident implies that there are only two degrees on the underlying scale of confidence. However, such an implication would certainly be unfortunate and clearly misguided, for there are more than just two properties (presumably, instances of properties) linked to the scale of confidence. Exactly as when first window is more transparent than the second one and the second is more transparent than the third, someone may be more confident that $\mathrm{p}$ than another person, and yet this second person may be more confident that $\mathrm{p}$ than the third. Clearly then, there are more than just two degrees on the underlying scales of transparency and confidence. But how, then to fit this with the idea that there are only two possible states of being confident that $\mathrm{p}$ (a maximal one or a minimal one) and only two states of being transparent (maximal and

\footnotetext{
${ }^{13}$ See the following context from Kennedy 2007, where 'transparent' can be interpreted as a minimal standard adjective: "Consider a context in which I am manipulating a device that changes the degree of tint of a car window from $0 \%$ (completely transparent) to $100 \%$ (completely opaque). (67a) can be felicitously uttered at the point at which I have almost reached $100 \%$ of tint, demonstrating both that opaque can have a maximum standard (I am denying that the glass is completely opaque) and that transparent can have a minimum standard (partial transparency).
}

(67) a The glass is almost opaque, but not quite. It's still transparent.

b The glass is almost transparent, but not quite. It's still opaque. 
minimal)? 14

The key point in replying to this worry is that states of being confident that p correspond to 'confident that p' in the positive form. The positive form of 'confident that p' is distinguished from comparative forms like 'is more confident than'. Within the scalar framework of the linguistics of gradable adjectives both comparatives and positive forms are derived by appeal to a measure function, degrees and a scale. The important point for us in the Kennedy and McNally framework is that they identify a special class of absolute gradable adjectives (following Unger 1975, and Rotstein and Winter 2004). The specificity of the absolute gradable adjectives is that the denotation of their positive form is determined once the relevant endpoint inherent to the very meaning of the adjective is fixed; whereas in the case of the more familiar relative gradable adjectives (e.g. 'tall', 'rich') the denotation of their positive form is determined through first fixing an utterly context-dependent threshold of application (not an inherent endpoint). The two-state conjecture focuses on the denotation of 'being confident that p' in the positive form. It is a thesis about being confident that $\mathrm{p}$ (and not directly about what it is for someone to be more confident that $\mathrm{p}$ than someone else is). The takeaway lesson from the linguistics of gradable adjectives is that, contrary to relative gradable adjectives, absolute adjectives will not allow any given degree on the underlying scale to fix the relevant threshold of application (for the positive form) in a given context. Only the maximal or minimal degrees are allowed to set the relevant threshold, or, more precisely, endpoint for the application of absolute adjectives. Now the present proposal is that (assuming that these linguistic observations are taken seriously) a state of being confident that $\mathrm{p}$, understood as the denotation of 'being confident that p' (positive form), can only be either a state that has a maximal 'amount' of confidence (one that satisfies a maximal standard) or a state that has any, even the slightest, 'amount' of confidence (one that satisfies a minimal standard). This is how we should understand the claim that there are only two possible

\footnotetext{
${ }^{14}$ Thanks to an anonymous referee for this journal for making me aware of this potential worry.
} 
states of being confident that p. It is not to claim that the underlying scale of confidence has only two possible degrees 15

Roughly put, what is meant here by 'state of being confident that p' is what the literature refers to by the talk of 'outright belief' or 'categorical belief' (however, see section 7 for more important details on how the present view maps onto the more familiar debates about categorical belief versus degrees of belief). According to the general approach that goes under the label of 'reductionism' the categorical, fixed state of belief reduces to some specific degree on an underlying scale (of, say, credences) ${ }^{16}$ Reductionism about belief amounts then to the view that there is only one state of (categorical) belief and it corresponds to some specific degree of belief (credence), but a reductionist need not be committed to the view that there is only one possible degree on the underlying scale of credences. Similarly, the present claim that there are only two possible states of being confident (i.e. denotation of 'being confident' in the positive form) doesn't commit us to the claim that there are only two degrees on the scale of confidence.

Third, and connected to the previous point, belief is associated on the present view with a (categorical) state of being confident. It is an assumption that the present proposal makes. Yet it is a common one. Belief is associated both in philosophical discourse and in the everyday context with confidence. Typically, philosophers accept that it makes sense to talk about degrees of confidence

\footnotetext{
${ }^{15}$ One way to further clarify the present claim is to see it as a claim about kinds of 'being confident that p' states. The idea is that one kind of state of being confident that $p$ is such that it requires a maximal 'amount' of confidence whereas the other is such that it requires only some 'amount' of confidence (i.e. any 'amount' of confidence is enough for one to be in a state of this second sort, like any amount of transparency is enough for a window to still count as partially transparent in a relevant context: see footnote 13 above). Thus, the account does allow for variations in the 'amount' of confidence that one may have when one is somewhat (minimally) confident that p. In the above case of manipulating the tint of a window, the utterance 63(a) 'The glass is almost opaque, but not quite. It's still transparent' comes out as true at more than one point during the process of changing the tint of the window. We can imagine that there is a continuum of states $x_{1}$ to $x_{n}$ such that state $x_{m+1}$ is a bit closer to the state of the window's being totally opaque than state $x_{m}$ is, but such that window is still transparent in all of them. I think something similar is allowed by the present account of being confident that p. The claim that there are only two possible kinds of states of being confident that $\mathrm{p}$, one subject to a minimal standard and the other subject to a maximal standard, doesn't preclude the possibility of there being variation in how much confidence one actually has when one is somewhat confident. Thanks again to an anonymous referee for this journal for making me aware of the need to clarify this point.

${ }^{16} \mathrm{Or}$, at any rate, to some condition on an underlying scale. Thanks to a referee for pointing to this specification.
} 
(a.k.a. degrees of belief) and outright (full, or all-or-nothing) belief. Many think that both are real and, moreover, somehow connected. Now, one may of course reject this assumption. Yet such a rejection would raise some puzzling questions that would have to be addressed if there were no connection between being confident and belief ${ }^{17}$ For instance, are there beliefs and degrees of belief in addition to being confident and degrees of confidence? But then, if yes, how should we think about epistemological principles that apply to these two pairs (for instance, would it be epistemically appropriate for one to believe that $\mathrm{p}$, while not being confident that $\mathrm{p}$ and so on) ${ }^{18}$ And how does the claim that both pairs exist fit with our knowledge about the limitations of our cognitive resources (we have only limited storage in memory, limited computational capacities, and so on)? One might actually think that parsimony favours the simpler view on which belief is associated with being confident (and degrees of belief with degrees of confidence). That is, not only would the view on which belief is associated

\footnotetext{
${ }^{17}$ One may object that strictly speaking the claim that belief and being confident are somehow connected is a weaker claim than the claim that belief just is being confident. Consequently, one might think that rejecting one need not mean rejecting the other, and while rejecting any connection between the two surely leads to some puzzling questions, merely rejecting the stronger claim need not. Moreover, it can be objected that the present proposal has to take up the stronger assumption in order to deliver on its promises. Again, I think this is a genuine worry that a full account of belief should address in detail. However, that task exceeds our present project, which is simply to put on the table a previously overlooked way of dealing with the lottery paradox and belief. With that being said, I nonetheless think that some of the questions posed below do appear puzzling even for less demanding views on the connection between belief and being confident. Now, even if these considerations are misguided, the belief-being confident identity assumption is not obviously implausible, and the fact that it makes possible a potential solution to the lottery paradox and that it provides a simple account of the epistemic justification of mental states in general (see below) surely speak in its favour. Finally, I would also like to point towards considerations from Engel 2012 against the idea that belief and acceptance are two genuinely distinct doxastic attitudes. Arguably, similar considerations may apply in the present context. Thanks to an anonymous referee for alerting me to this issue.

${ }^{18}$ One might think that there is nothing puzzling here: utterances like 'I think that p, but I am not at all confident that p' seem fine in some contexts. Assuming that ' $I$ think that p' expresses a state of belief, one might argue that this shows that belief and being confident should not be associated too closely. While I agree that this is something we can felicitiously assert, I am not sure that it actually speaks against my proposal here. This data, I want to suggest, is compatible with the idea that 'think that p' can express a minimal standard belief, or a state of being somewhat confident (see also below on the thesis that belief is 'weak', cf. Hawthorne, Rothschild and Spectre 2016), while 'I am confident that p', by default, expresses a maximal standard belief, or a state of being maximally confident (see above on Kennedy's suggestion that for pragmatic reasons in the case of closed-scale adjectives the strongest interpretations are favoured over weaker ones, cf. Kennedy 2007: section 4.3). On this reading, the data in question doesn't speak against the present proposal. Indeed, it fits very neatly within our framework. Thanks again to an anonymous referee for bringing this to my attention.
} 
with being confident be a simpler and more elegant view ontologically speaking, it would also avoid demanding commitments about our psychology. The simpler thesis (the association of belief with being confident) doesn't posit any need for extra storage in our limited memory and other cognitively expensive tasks (see Weisberg, forthcoming for similar considerations with respect to dualist views about belief).

Finally, note also that some of the recent developments in the belief literature may actually fit well with the present framework. In particular, distinguishing between weak and strong senses of 'belief' seems to fit well with the present approach. On one view belief is weak (see Hawthorne, Rothschild and Spectre 2016), in the sense of not requiring high probability. Yet some authors seem to think that there has to be another sense (the sense that is popular in philosophical contexts) of 'belief' according to which belief is strong and requires maximal probability (see Greco 2015, see also Dorst 2019). If the present proposal is on the right track, it is then unsurprising that philosophers feel the need to distinguish weak belief from strong belief. But again, we shall return to the comparison of the present view with recently popular approaches in section 7 .

Now with these clarifications in mind we are in a position to see how the twostate conjecture understood in the above sense can solve the lottery paradox. Given that belief that p can be associated either with being maximally confident that $\mathrm{p}$ or with being somewhat confident that $\mathrm{p}$, the lottery paradox argument (1.1)-(1.6) can be understood in three distinct ways. First, we can read it as appealing to different interpretations of belief in different premises (say, minimal interpretation in 1.1 and 1.2. but maximal in 1.4). On this understanding the argument is simply not valid since it would commit the fallacy of equivocation. Second, we can read it as appealing throughout 1.1 to 1.6 to belief in the minimal sense. Third, we can read it as appealing to belief in the maximal sense. These last two readings avoid committing a fallacy, since they both hold the sense of belief the same in all premises. Yet neither of these leads to a paradox, for on neither reading is the argument sound. In both cases, we have a rather clear 
grasp of which premises should be rejected. Let us explore this in some more detail.

If one's belief that $p$ is understood throughout (1.1)-(1.6) as one being confident that $\mathrm{p}$ in the minimal sense, then the premise (1.4) can be reasonably questioned (i.e. "For all S, for all p, q, if $\mathrm{S}$ is justified to believe that $\mathrm{p}$, and $\mathrm{S}$ is justified to believe that $q$, then $S$ is justified to believe that ( $p$ and $q) ")$. That is, it seems that the Conjunction principle doesn't hold for being somewhat confident. One may well be justified in being minimally (somewhat) confident that one's friend A will come to the party, and one may be justified in being minimally (somewhat) confident that one's friend B will come to the party, and so on for all of one's invited friends, and yet it need not be the case that one is justified in being minimally (somewhat) confident that all of one's invited friends will come 19

Note that other premises seem to hold with respect to being somewhat confident that p. In particular, evidential probability provided by the statistical considerations about the lottery case seems to be high enough for the purposes of being somewhat confident (cf. premise 1.2). Also, the High principle (premise 1.1) is appealing for being somewhat confident. If it is highly probable that this horse will win the race (e.g. it has an extremely high rate of success this year; see the example from (20a)), then one is justified in being at least somewhat confident that the horse will win the race.

If one's belief that $\mathrm{p}$ is understood throughout (1.1)-(1.6) as one being maximally confident that $\mathrm{p}$, then the premise (1.2) can be reasonably questioned (i.e. "For any ticket in a fair and large lottery, that ticket $\mathrm{n}$ lost (tn) has high enough probability on S's evidence"). The evidential probability of the lottery propositions (given the statistical information only) is never high enough in the relevant sense for being justified in being maximally confident that a given ticket

\footnotetext{
${ }^{19}$ Cf. Hawthorne 2003: 48-49 and Smith 2016: 72-73 for this sort of example, which might appear as a variant of the famous Preface Paradox, cf. Makinson 1965. Note, however, that this example doesn't give rise to the preface paradox within the present setting. For we are not suggesting that for any individual invitee, the host may be maximally confident that she/he will attend. And even if one were to have such a maximal confidence state, it would not comply with the relevant standards for justification of maximal confidence.
} 
is a loser. Justification standards for being maximally confident that $\mathrm{p}$ are akin to standards for being justified in being certain that p. And, clearly, these standards are not met in the case of the lottery propositions (i.e. a fair lottery, with no insider knowledge about the winner, and mere statistical information as the evidential basis).

Note also that other premises seem to hold on the maximal reading of belief. The conjunction principle clearly holds. If one is justified in being maximally confident that John is in Paris and one is justified in being maximally confident that Mary is in Paris, then one is justified in being maximally confident that both John and Mary are in Paris. The High principle (i.e. premise (1.1) "For all $\mathrm{S}$, for all $\mathrm{p}$, if $\mathrm{p}$ has high enough probability on $\mathrm{S}$ 's evidence, then $\mathrm{S}$ is justified to believe that $\mathrm{p} "$ ) is also respected on the maximal reading of belief. High evidential probability may matter for justification of maximal belief. If the claim that John is in Paris has high enough probability on my evidence, then I may well be justified to believe that John is in Paris.

Distinguishing two sorts of belief states enables us to avoid contradictory conclusions. Intuitively, the Conjunction principle fails for one sort of belief (i.e. for being somewhat confident that $\mathrm{p}$ ) and hence the contradiction is avoided on this reading. And intuitively, premise 1.2 fails for the other sort of belief (i.e. lottery propositions never have high enough probability on one's evidence to justify being maximally confident in them). Hence, again the contradiction is avoided on this reading as well. Moreover, and this is an important advantage of the present view, the relevant intuitions are respected within this approach. It is still the case that Conjunction holds in an important sense, and it is still the case that the High principle holds and with respect to some purposes lottery propositions have high enough probability. In sum the paradox only arises when we collapse the two states together and maintain that they obey the same epistemic principles and requirements. The paradox is avoided in an ecumenical way by associating belief with two possible states of being confident that p: a maximal one and a minimal one. 
One consequence of the present proposal is that it entails that there is one sort of state of being confident that $\mathrm{p}$ that is more risk-tolerating than another sort of state of being confident that $\mathrm{p}$. Thus, being somewhat confident that $\mathrm{p}$ is on this view a risk-tolerating state in the sense that its justification is not impeded just because there are chances that the relevant proposition is not true. Meanwhile, on the other hand, the state of being maximally confident that $\mathrm{p}$ is in a way a risk-averse state and is more like certainty. This result is entailed by independent considerations about more general classification of mental states. This then can be taken to be additional independent evidence in favour of the two-state conjecture, or so I suggest in the next section.

\section{No paradox for (risky) emotions or certainty}

In contemporary epistemology epistemic justification is typically associated with doxastic states (belief, suspension, and disbelief). However, from a bigger-picture perspective it makes sense to ask, first, whether epistemic justification can be possessed by mental states more generally, and if yes, whether there is some more general classification of mental states with respect to epistemic standards that applies to them. The answer to the first question seems to be affirmative. Even though epistemologists have not written much about it, the idea that certain non-doxastic states can also be epistemically justified is not alien outside epistemology. For instance, it is rather a popular view within the neighbouring field of the philosophy of emotions. It is often claimed in the philosophy of emotions that (at least some) emotions (and not only beliefs) can be epistemically justified (see Gordon 1987, Deonna and Teroni 2012, Echeverri, forthcoming, among others). One's fear that one will have an accident today may not be epistemically justified if it is based on notoriously unreliable sources, say, on reading a horoscope; whereas one's fear that a dog will bite one, based on seeing an angry dog running towards one, seems to be justified in a specifically epistemic sense (which should be distinguished from other ways in which an emotion may 
be evaluated as appropriate; see Gordon 1987:35, de Sousa 2002: 251, Deonna and Teroni, 2012, pp.6-7).

It also appears that there are non-doxastic non-affective states that can possess epistemic justification. Take, for instance, guessing that p, conjecturing that $\mathrm{p}$, supposing that $\mathrm{p}$, being worried that $\mathrm{p}$ (though, 'being worried' also has an emotional reading), fancying that $\mathrm{p}$, considering that $\mathrm{p}$, speculating that $\mathrm{p}$, surmising that $\mathrm{p}$. These states can be evaluated from a specifically epistemic point of view. For instance, given that Anthony knows that Hillary lost the 2016 US presidential election, there would be something inappropriate in his suspecting that Hillary is the actual president of the USA. Crucially, it seems that the sense in which it would be inappropriate is specifically epistemic and not different from a sense in which Anthony's belief that Hillary is the actual president of the USA would be inappropriate.

Now, with respect to the second question, the following classification seems to make at least prima facie sense. On one hand, there is the general group of 'risk-tolerating states' or 'risky states' for short. A common feature of these is that they can be appropriately held towards propositions that have a small chance of being true. The evaluation here is an epistemic one. Certain emotions (e.g. fearing that $\mathrm{p}$, hoping that $\mathrm{p}$ ) as well as non-affective states (e.g. guessing that $\mathrm{p}$, hypothesizing that $\mathrm{p}$ and so on) seem to belong to this general group of mental states.

On the other hand, there are 'risk-averse' states that are more like certainty states. Characteristically these states require a high degree of evidential support, indeed, the maximal one for epistemic justification. The state of being certain is the paradigm state of this group. In order to be epistemically justified in being certain that $\mathrm{p}$, one needs to have a maximal degree of evidential support. Being sure that $\mathrm{p}$ is another state belonging to this group. And, arguably, (at least certain) factive emotions also belong to this group. If one regrets that one sold one's car without, say, knowing that one sold it, there seems to be something untoward in such a state (see Gordon 1987:39, for similar observations, and for 
a classification of emotions (with propositional content) into those that require knowledge and those that preclude knowledge). Assuming that when one knows that $\mathrm{p}, \mathrm{p}$ has the maximal degree of evidential support for one, we can conclude that regretting that $\mathrm{p}$ requires maximal evidential support for being epistemically justified. Traditionally, other factive emotions include being angry that $\mathrm{p}$, being happy that $\mathrm{p}$, being sad that $\mathrm{p}$, and others (see also Dietz 2018).

The general classification of states into risky and certainty-like (or not risky) ones is vindicated by a further observation about how various mental states deal with parallel versions of the lottery paradox-like arguments.

Consider the following argument, that parallels the standard lottery paradox argument, for risk-tolerating states:

\section{The Lottery Argument for Risky States}

(2.1.) For any agent $\mathrm{S}$, for all $\mathrm{p}$, if a proposition $\mathrm{p}$ has high enough probability on $\mathrm{S}$ 's evidence, then $\mathrm{S}$ is epistemically justified to be worried that $\mathrm{p}^{20}$ (HIGH-RISKY).

(2.2) For any ticket in a fair and large lottery, that ticket $\mathrm{n}$ lost (tn) has high enough probability on S's evidence 21

(2.3.) $\mathrm{S}$ is epistemically justified to be worried that tn. $[2.1 ; 2.2]$

(2.4.) For any subject $\mathrm{S}$, for all propositions, if $\mathrm{S}$ is justified to be worried that $\mathrm{p}$, and $\mathrm{S}$ is justified to be worried that $\mathrm{q}$, then $\mathrm{S}$ is justified to be worried that (p and $q)$. (CONJUNCTION-RISKY)

(2.5.) $\mathrm{S}$ is justified to be worried that (ticket 1 lost, and ticket 2 lost, ..., and ticket $\mathrm{m}$ lost). $[2.3 ; 2.4]$

(2.6.) $\mathrm{S}$ is not justified to be worried that (ticket 1 lost, and ticket 2 lost, ..., and ticket $\mathrm{m}$ lost). [Knowledge that one ticket won]

Clearly, (2.1)-(2.6) doesn't lead to a paradox. We grasp clearly which premise is false. Namely, premise (2.4) has to go in the case of being worried that p,

\footnotetext{
${ }^{20}$ The same goes for other risky states (being afraid that $\mathrm{p}$, suspecting that $\mathrm{p}$, etc.). The rest of the argument should be read in the same sense: premises are not only about being worried that p, but about any risky state. Also, again, the focus is on propositional justification.

${ }^{21}$ Again we are assuming that $\mathrm{S}$ knows that the lottery is fair, has one winner, and $\mathrm{S}$ has no other insider information. The lottery has been drawn but results have not yet been announced.
} 
hoping that $\mathrm{p}$, hypothesizing that $\mathrm{p}$ and so on. Justification doesn't even appear to be closed under conjunction for being worried and similar states. Imagine the following example. Nancy cannot find her little brother. She knows that he might have taken the dangerous road A. She also knows that he might have taken road B which has heavy traffic. She seems epistemically justified to be worried that he took road A. And she seems epistemically justified to be worried that he took road B. But from her being justified in being worried that he took road A, and her being equally justified in being worried that he took road B, it doesn't follow that she is justified in being worried that he took both, road A and road B. For one thing, she may just know that he didn't take both road A and road $\mathrm{B}$, for it is impossible to take both 22

Note also that the rest of the underlying principles in the Lottery Argument for Risky States seem plausible. High probability is enough for justification for being worried that $\mathrm{p}$, being hopeful that $\mathrm{p}$ etc. And lottery propositions do appear to have high enough probability for the purpose of epistemic justification of being worried that $\mathrm{p}$ (and so on).

Now, with respect to being certain that $\mathrm{p}$, being sure that $\mathrm{p}$, regretting that $\mathrm{p}$ and so on, there is no paradox either. But in this case, the reason is not the same. While the Conjunction principle holds for being certain (being sure, regretting, etc.) the equivalent to the premise (1.2) and (2.2) fails for being certain and being sure and so on. Lottery propositions never have high enough evidential probability (on statistical information only) for being certain, being sure, regretting and so on that a ticket lost.

These differences in patterns of reaction to the lottery paradox-like argument are captured by the general classification of risky versus certainty-like states. Closure for justification doesn't apply to risky states, while lottery propositions

\footnotetext{
${ }^{22}$ Other cases without impossibility are also available. Maybe Nancy is justified in fearing that her brother will be attacked, and she is justified in fearing that her brother will get into a road accident, and she is justified in fearing that her brother will fall off a cliff and so on. But, given the high number of such possible negative outcomes she is probably not justified in being worried that her brother will have them all (i.e. that he will be attacked and involved in a road accident, and fall off a cliff etc.). The conjunction of all of them, though possible, is so improbable that being worried about them all occurring at once might just be epistemically unjustified.
} 
cannot be justified for certainty-like states.

This result, I take it, provides some additional plausibility for the two-state conjecture. For being somewhat confident clearly fits into the pattern of risky states, while being maximally confident fits into the pattern of certainty-like states. Postulating a distinct category of belief that doesn't fit into this general classification not only leads to the lottery paradox, it is also less parsimonious. It postulates an extra ontological category. If there were such a separate category of belief only, we would need an extra explanation for why there is a state that doesn't fit one of the more general patterns.

\section{Two-state conjecture and belief dualism}

The venerable question concerning the relation between belief and degrees of belief (see Ramsey 1926 for a locus classicus) has received a significant revival in recent epistemological debates (see Foley 2009, Clarke 2013, Leitgeb 2013, 2014, Buchak 2014, Ross and Schroeder 2014, Greco 2015, Weatherson 2016, Jackson 2018, Dorst 2019, Weisberg, forthcoming, among others). The main positions within the present debate are, roughly, as follows. On one hand there is an increasingly popular dualist approach. Abstracting from specificities of particular views, according to dualism there exist two distinct mental states: graded confidence (degrees of belief, typically understood in terms of credences - corresponding to the subjective probability function), and (non-graded) belief. Typically, it is assumed by dualists that both have psychological reality and each fulfills some specific cognitive functions. Importantly, neither state reduces to the other. (Buchak 2014, Ross and Schroeder 2014, Weatherson 2016, Weisberg, forthcoming are among the recent dualist accounts.) On the other hand, there are reductionists, who reduce one of the above states to the other. According to one reductionist trend, belief ultimately reduces to some degree of belief. A paradigmatic reductionism here goes under the name of the 'Lockean thesis' that aims to specify the probabilistic threshold necessary for (rational) belief 
(cf. Christensen 2004, Sturgeon 2008, Foley 2009, see also the 'Humean thesis' in Leitgeb 2013, 2014, even though Leitgeb remains uncommitted with respect to the ontology of these states). According to a radically different version of reductionism, degrees of belief ultimately can be reduced to belief (see Holton 2008, 2014, Easwaran 2015).

Now it is only natural to ask how our two-state conjecture fits into this more popular debate between dualists and reductionists about belief and degrees of belief. And furthermore, in what sense, if any, the present two-state conjecture based solution to the lottery paradox is any different from what recent proponents of dualism or reductionism have proposed or at least are in a position to propose 23

A quick reply to the first question is that there is no one self-imposing way to map the present view onto the dualist-reductionist debate. For the present proposal can be seen as questioning some of the very assumptions that (many) dualists and reductionists appear to take for granted. To see this better, consider the following quotation, which sums up very nicely some of the central assumptions that people in that debate appear to be making:

"Belief is a categorical attitude in the sense that it is not degreed; either one believes a proposition or one does not. [...] However, sometimes our attitudes are more complex than simple beliefs. [...] Credences are, in many ways, similar to the more everyday attitude of confidence, and roughly correlate with the subjective probability that some proposition is true. [...] Recently, three views about the relationship between belief and credence have emerged. [...]" (Jackson 2018: $1-2)$.

Here I would like to put forward two observations in particular. First, it does seem to be a common assumption, at least among dualists, that the graded counterpart state of (non-graded) belief is the state of confidence. Reductionists

\footnotetext{
${ }^{23}$ Thanks to an anonymous referee for this journal for making me aware of the need to clarify these points.
} 
are not eliminitivists (cf. Jeffrey 1970), and hence recognize that it makes sense to think of two distinct states, one graded, the other non-graded, in that way (i.e. non-graded belief versus confidence), even though it can be shown that one reduces to the other. On the present account confidence is not a state. Being confident that $\mathrm{p}$ is a state. More precisely, being somewhat confident that $\mathrm{p}$ is a state that requires the minimal amount of confidence (i.e. hitting the lower endpoint on the underlying scale of confidence), while being maximally confident that $\mathrm{p}$ is a state that requires the maximal amount of confidence (i.e. hitting the upper endpoint on the underlying scale of confidence) - exactly as being transparent is a state that may either require hitting the upper endpoint on the underlying scale of transparency or hitting the lower endpoint on the underlying scale of transparency.

Second, it does seem to be a common and fundamental assumption within the dualism-reductionism debate that categorical states are non-graded states. Categoricity is associated in this context with being all-or-nothing, with either being in a state or not being in the relevant state (see the quotation above), with having on-off characteristics, with being binary. On the present account, however, being categorical in this sense is not incompatible with being gradable. That is, the very formulation of the question on which dualists and reductionists are supposed to disagree, is misleading according to the present account. On the present view being confident just is either being minimally confident or maximally confident. It is hitting the minimal or maximal endpoint of confidence. But the matter of hitting one of these endpoints is all-or-nothing, on-off, a binary matter: either one has the specified amount of confidence or one doesn't. And this is a general point: a window is either transparent or not, it is all-ornothing in the sense of either hitting the relevant standard for transparency or not, even though there are degrees of transparency and one window can be more transparent than another.

Now, of course, we still want to preserve the idea that belief has the property of being resilient in the light of new information, or in other terms, that it 
manifests a sort of crispness (compare to the 'crisp judgment effect' in Kennedy 2007) ${ }^{24}$ But as the insights from absolute gradable adjectives have taught us, we can have crispness and gradability at the same time. We should not think of gradability on the model of being rich, or tall only. Being transparent, being dry, being open and so on are better paradigms for thinking about gradability in this context. Crucially, what counts as transparent, or dry, for that matter, doesn't vary completely depending on a context, but have intrinsic standards that provide a sense of crispness. Similar considerations apply to belief. Importantly, the categoric aspect of belief, understood in this way, need not entail non-gradability ${ }^{25}$

Moreover, and in particular, contra reductionists, it is not clear at all that the states of being somewhat confident that $\mathrm{p}$, and being maximally confident that $\mathrm{p}$ cannot fulfill what has been identified in the literature as central roles of graded state (partial belief, confidence), and categorical belief respectively. For instance, it makes sense to think of being confident that $\mathrm{p}$ as being disposed to treat p as true in one's reasoning (cf. Ross and Schroeder 2014), as having settled on an issue or closed the matter for oneself (Weisberg, forthcoming) to take $\mathrm{p}$ for granted (cf. Weatherson 2016), to rule out worlds in which not- $p$ holds (cf. Buchak 2014: 286). I don't see any principled reason to think that the state of being maximally confident cannot play any of these roles that have been associated with 'categorical' belief in the literature.

Now, upon reflection, one might think that the above observations about the

\footnotetext{
${ }^{24}$ I think it makes sense to associate crispness with what some authors call 'being given' or 'being taken for granted'. See Weisberg: "Full beliefs provide premises that are treated as givens in reasoning, while partial beliefs are used as weights." Weisberg, forthcoming: 30

${ }^{25}$ Having the maximal/minimal degree of confidence is having a degree of confidence. Admitting of a degree is being gradable. Compare to radically different, clearly non-gradable items. Being next, being left, being digital, for instance, has no degree whatsoever. On the other side, being tall, rich and so on, is gradable and vague: there is no inherent crispness in what counts as rich or tall. Being tall or rich depends entirely on the specificities of context. But to suppose that something is either non-gradable (akin to being next or being digital) or tall-like gradable, is a false dilemma. There is the middle ground of being transparent, being dry, being open and so on, that comes in degrees but has inherent standards and crispness.

${ }^{26}$ See Weisberg: "Two characteristics distinguish this state [i.e. the state of full belief that is not 'just being highly confident'] . First, we become disposed to rely on P-to use it as a premise in future reasoning, to assume it in decision-making, and to assert it. [...] Second, we become resistant to re-opening deliberation - we treat the question whether $\mathrm{P}$ as settled." Weisberg, forthcoming: 6 .
} 
problematic assumptions within the dualist-reductionist debate notwithstanding, the two-state conjecture fits rather well with credence 1 (contextualist) reductionism (or the Certainty View, cf. Clarke 2013, Greco 2015). According to Greco: "The simple view [i.e. roughly, a sort of credence 1 reductionism] is the view that binary belief is maximal degree of belief - it is the endpoint of the scale of degreed belief." (Greco 2015: 179). But this characterization just seems to correspond to what we are (at least, partly) suggesting here. Two points of caution should be noted, nevertheless. First, the understanding of the key aspects of the underlying scale of confidence (for the states of being confident) cannot be seamlessly interpreted within the probabilistic framework. That is, degrees of confidence, as understood here, don't correspond straightforwardly to degrees of probabilities ${ }^{27}$ For instance, not being confident at all doesn't seem to correspond to degree 0 on the confidence scale, as it might be expected to be within the probabilistic framework (see Williamson ms, and Hawthorne and Logins, ms for considerations along similar lines) ${ }^{28}$ Second, on the present model there are two states of being confident that p: the minimal one and the maximal one. Credence 1 reductionism doesn't posit two states of belief. If anything, only the part about the state of being maximally confident that $\mathrm{p}$ from our view might be associated with the credence 1 view of belief.

Before concluding, two quick observations are in order with respect to the second of the above questions, that is, the question about the alternative solutions to the lottery paradox within the dualist-reductionist debate.

A solution given Buchak's dualism (cf. Buchak 2014), for instance, is to claim that categorical belief in a lottery proposition can never be justified, because categorical belief in a proposition based only on statistical considerations can never be justified. The present two-state solution has the advantage over the solution implicit in Buchak's framework in that it respects the apparent intuition that in a sense categorical ('categorical' being understood in the above specified

\footnotetext{
${ }^{27}$ Which is not to say that evidential probability cannot play a significant role with respect to justification of the states of being confident.

${ }^{28}$ I would also like to thank an anonymous referee for this journal for stressing this point.
} 
sense) belief in a proposition based on high statistical probability may still be justified. This may even happen in the case of lottery propositions. One may be justified in being somewhat confident (belief in minimal interpretation) that a lottery ticket is a loser. I submit that this proposal fits better with our intuitions about highly probable propositions that have only statistical support.

Credence 1 (contextualist) reductionism also appears to have resources to avoid the contradiction in the case of the lottery paradox. If belief is understood as requiring probability 1 , i.e. maximal credence, then one might suggest that one never really believes lottery propositions, for they never get credence 1 . Hence, the paradox doesn't even get off the ground in the first place. However, I submit that the present proposal has an advantage over this approach. For it still respects the intuition that we may believe in a sense that a lottery ticket is a loser (we may be somewhat confident about it). Moreover, the present proposal is not committed to the subjective probability view of degrees of belief, and may be adapted to deal with the lottery paradox that also arises for views on which there are strictly speaking no credences. As seen above (see section 2), a version of the lottery paradox may still be generated for such views given the assumption that high evidential probability matters for justification of belief. With respect to such a view, the present approach maintains that there is a difference to be made among being somewhat and being maximally confident even if there were no credences. The present approach to the lottery paradox appears to be more inclusive and more ecumenical in the sense of being neutral on what exactly one's take is on the nature of degrees of belief and being able to give due respect to most of the intuitions behind the reasoning that has been taken to lead to the paradox.

\section{Conclusion}

In this article we have reconsidered the Lottery Paradox. The solution to the paradox relies on a distinction between being somewhat confident and being 
maximally confident. Once we acknowledge that belief can be understood either in the minimal or in the maximal sense and that different principles for justification apply to these different states, we can see which premises of the paradox on which reading can be rejected. While conjunction fails for being somewhat confident, the probability of lottery propositions is never high enough for justification of being maximally confident that $\mathrm{p}$. This two-state conjecture was elaborated on the background of recent work on gradable adjectives, in particular on the basis of insights about absolute gradable adjectives. It also appears to receive extra plausibility once we consider a bigger-picture distinction between risky and certainty-like states, for which there is no lottery paradox. Finally, the two-state conjecture and the present solution to the lottery paradox have some similarities with some of the recent views within the dualist-reductionist debate about degrees of belief and belief, but is also an importantly different approach, since it relies on an attempt to rethink some commonly held assumptions about graded and categorical belief. The upshot of that issue is that on the present account being gradable and being categorical need not be incompatible.

Acknowledgments Many thanks to Richard Dub, Jeremy Goodman, John Hawthorne, Tristram Oliver-Skuse, Edgar Phillips, Travis Timmerman, Alexis Wellwood, audiences at University of Geneva, University of Fribourg, SOPHA 2018 congress, and two anonymous referees for this journal for discussion and comments on earlier version of this paper. The research work that led to this article was supported by the Swiss National Science Foundation grants number 171464 and 169293.

\section{References}

[1] Lara Buchak. Belief, credence, and norms. Philosophical Studies, 169(2):1$27,2014$. 
[2] Fabrizio Cariani, Paolo Santorio, and Alexis Wellwood. Comparative confidence. ms., 2017.

[3] David Christensen. Putting Logic in its Place: Formal Constraints on Rational Belief. Oxford University Press, 2004.

[4] Roger Clarke. Belief is credence one (in context). Philosophers' Imprint, $13: 1-18,2013$.

[5] Roger Clarke. Contextualism about belief ascriptions. In Jonathan Jenkins Ichikawa, editor, Routledge Handbook of Epistemic Contextualism, pages 400-410. Routledge, 2017.

[6] Stewart Cohen. Contextualist solutions to epistemological problems: Scepticism, gettier, and the lottery. Australasian Journal of Philosophy, 76(2):289-306, 1998.

[7] Ronald B. de Sousa. Emotional truth. Proceedings of the Aristotelian Society, 76(76):247-63, 2002.

[8] J.A. Deonna and F. Teroni. The Emotions: A Philosophical Introduction. Routledge, 2012.

[9] Christina Dietz. Reasons and factive emotions. Philosophical Studies, 175(7):1681-1691, 2018.

[10] Kevin Dorst. Lockeans maximize expected accuracy. Mind, page fzx028, forthcoming.

[11] Igor Douven and Timothy Williamson. Generalizing the lottery paradox. British Journal for the Philosophy of Science, 57(4):755-779, 2006.

[12] Philip A. Ebert, Martin Smith, and Ian Durbach. Lottery judgments: A philosophical and experimental study. Philosophical Psychology, pages 129 , forthcoming. 
[13] Santiago Echeverri. Emotional Justification. Philosophy and Phenomenological Research, forthcoming.

[14] Pascal Engel. Trust and the doxastic family. Philosophical Studies, 161(1):17-26, 2012.

[15] Richard Foley. Justified inconsistent beliefs. American Philosophical Quarterly, 16(4):247-257, 1979.

[16] Richard Foley. Beliefs, degrees of belief, and the lockean thesis. In Franz Huber and Christoph Schmidt-Petri, editors, Degrees of Belief, pages 37-47. Springer, 2009.

[17] Jie Gao. Credal pragmatism. Philosophical Studies, pages 1-23, forthcoming.

[18] Robert M. Gordon. The Structure of Emotions: Investigations in Cognitive Philosophy. Cambridge University Press, 1987.

[19] Daniel Greco. How i learned to stop worrying and love probability 1. Philosophical Perspectives, 29(1):179-201, 2015.

[20] Daniel Greco. How i learned to stop worrying and love probability 1. Philosophical Perspectives, 29(1):179-201, 2015.

[21] Gilbert Harman. Change in View. MIT Press, 1986.

[22] John Hawthorne. Knowledge and Lotteries. Oxford University Press, 2004.

[23] John Howthorne and Artūrs Logins. Graded epistemic justification. Unpublished Manuscript, ms.

[24] Christopher Kennedy. Vagueness and grammar: The semantics of relative and absolute gradable adjectives. Linguistics and Philosophy, 30(1):1-45, 2007. 
[25] Christopher Kennedy and Louise McNally. Scale structure, degree modification, and the semantics of gradable predicates. Language, pages 345-381, 2005.

[26] Peter Klein. The Virtues of Inconsistency. The Monist, 68(1):105-135, 1985.

[27] Thomas Kroedel. The lottery paradox, epistemic justification and permissibility. Analysis, 72(1):57-60, 2012.

[28] Henry E. Kyburg. Probability and the Logic of Rational Belief. Middletown, CT: Wesleyan University Press, 1961.

[29] Maria Lasonen-Aarnio. Unreasonable knowledge. Philosophical Perspectives, 24(1):1-21, 2010.

[30] Hannes Leitgeb. The stability theory of belief. The Philosophical Review, 123(2):131-171, 2014.

[31] Hannes Leitgeb. The Stability of Belief. Oxford University Press, 2017.

[32] David Lewis. Elusive knowledge. Australasian Journal of Philosophy, 74(4):549-567, 1996.

[33] Clayton Littlejohn. Justification and the Truth-Connection. Cambridge University Press, 2012.

[34] Clayton Littlejohn. Don't Know, Don't Believe: Reply to Kroedel. Logos and Episteme, 4(2):231-238, 2013.

[35] Dana K. Nelkin. The lottery paradox, knowledge, and rationality. The Philosophical Review, 109:373-408, 2000.

[36] Jacob Ross and Mark Schroeder. Belief, credence, and pragmatic encroachment1. Philosophy and Phenomenological Research, 88(2):259-288, 2014.

[37] Martin Smith. What else justification could be. Nous, 44(1):10-31, 2010. 
[38] Martin Smith. Between Probability and Certainty. Oxford Universit Press, 2016.

[39] Roy Sorensen. Epistemic paradoxes. In Edward N. Zalta, editor, The Stanford Encyclopedia of Philosophy. Metaphysics Research Lab, Stanford University, fall 2017 edition, 2017.

[40] Julia Staffel. Beliefs, buses and lotteries: Why rational belief can't be stably high credence. Philosophical Studies, 173(7):1721-1734, 2016.

[41] Travis Timmerman. The Persistent Problem of the Lottery Paradox: And its Unwelcome Consequences for Contextualism. Logos 83 Episteme, 4(1):85-100, 2013.

[42] John Turri and Ori Friedman. Winners and losers in the folk epistemology of lotteries. Advances in experimental epistemology, pages 45-69, 2014.

[43] Peter Unger. Ignorance. Oxford University Press, 1975.

[44] Brian Weatherson. Can we do without pragmatic encroachment? Philosophical Perspectives, 19(1):417-443, 2005.

[45] Brian James Weatherson. Games, beliefs and credences. Philosophy and Phenomenological Research, 92(2):209-236, 2016.

[46] Jonathan Weisberg. Belief in psyontology. Philosopher's imprint, forthcoming.

[47] Timothy Williamson. Knowledge and its Limits. Oxford University Press, 2000.

[48] Timothy Williamson. Ambiguous rationality. Episteme, 14(3):263-274, 2017.

[49] Timothy Williamson. Justifications, excuses, and sceptical scenarios. The New Evil Demon. Oxford University Press, Oxford, forthcoming. 